\title{
Combining Ability Analysis of Fusarium Head Blight Resistance in European Winter Wheat Varieties
}

\author{
V. Šíp, J. ChrPovÁ*, L. ŠTĚrbovÁ and J. PALICOVÁ \\ Crop Research Institute, Prague, Czech Republic \\ (Received 16 May 2016; Accepted 10 October 2016; \\ Communicated by X.F. Zhang)
}

\begin{abstract}
The aims of the present study were to estimate the general combining ability (GCA) and the specific combining ability (SCA) effects controlling type II FHB resistance across environments in a set of European winter wheat varieties and, for purposes of future selection, to identify potential combinations of parents with suitable levels of FHB resistance. Parental varieties as well as $F_{1}$ generations were evaluated under both field and greenhouse conditions in two years. The results of the present study indicate that in the $F_{1}$ generation mean DON content was relatively lowest after crossing of moderately resistant parents (Sakura/Bakfis, Sakura/Federer, Petrus/Bakfis, and Sakura/Petrus), and mean DON content is low also after crossing the moderately resistant Bakfis variety with the susceptible Biscay and Cubus varieties. Evaluation of crosses in the $F_{1}$ generation was followed by evaluation of selected crosses (derived from the Bakfis and Sakura varieties) in the $\mathrm{F}_{2}$ generation. Correlations between $F_{1}$ and $F_{2}$ were highly significant in relation both to their DON content and visual symptom score (VSS), as well as between the individual experiments (and in the different years). The only exception was in the case of the 2014 field experiment, when inoculation was successful but conditions were not optimal for the disease to progress and DON to accumulate. The selection of a suitable parental variety (with a high GCA) can markedly influence the success rate of breeding for resistance to FHB. Detection of high SCA in the $\mathrm{F}_{1}$ generation is important for directing breeders to promising combinations for achieving FHB resistance. It was demonstrated here that low DON content may be achieved even after crossing a moderately resistant variety with susceptible varieties. Another possibility is to make use of heterosis directly for acquiring resistance in hybrid wheat (for decreasing DON content and manifestation of symptoms).
\end{abstract}

Keywords: common wheat, DON content, Fusarium culmorum, combining ability, heterosis

Abbreviations: FHB: Fusarium head blight, GCA: General combining ability, SCA: Specific combining ability, DON: mycotoxin deoxynivalenol

\footnotetext{
*Corresponding author; E-mail: chrpova@vurv.cz
} 


\section{Introduction}

Fusarium head blight (FHB) is one of the most damaging diseases in small-grain cereals, and particularly in years with intensive rainfall. FHB resistance is polygenic, and its expression is highly influenced by the environment. Resistance to FHB in small grain cereals is inherited predominantly as a quantitative trait in an additive-dominance model (Bai et al. 2000; Jiang and Ward 2006). In susceptible cultivars, the predisposition to produce the mycotoxin deoxynivalenol (DON) is of key importance, but in highly resistant cultivars resistance is the major factor in suppressing disease development and DON accumulation (Mesterházy 2002). Environmental conditions play a crucial role in FHB's development in wheat, and variation in FHB symptom expression due to environmental interactions remains a major challenge in terms of accurately assessing FHB resistance.

Resistance breeding is the most effective and elegant way to control for FHB, which causes yield losses and leads to contamination of feed and foodstuffs by harmful mycotoxins (Becher et al. 2013). It was demonstrated by Šíp et al. (2007) that moderate resistance in combination with fungicide treatment may result in reducing DON by as much as $89 \%$ (while reducing pathogen DNA content by as much as $96 \%$ ).

Because it is believed that appropriately utilizing sources of even moderate resistance can accelerate the development of wheat cultivars resistant to FHB, more attention should undoubtedly be given to identifying parental combinations with suitable levels of FHB resistance (Zwart et al. 2008). Single-cross prediction based on mid-parent performance shows promise for simple and highly heritable traits, but its use is hampered for more complex traits due to a masking by dominance effects (Smith 1986; Oettler et al. 2005). Mid-parent performance could serve as a moderate indicator for FHB resistance in singlecross triticale hybrids (Boeven et al. 2016). Statistically significant effects for both general combining ability (GCA) and specific combining ability (SCA) in diallels of winter wheat have been reported in point inoculation trials with $F$. graminearum (Hall and Van Sanford 2003) and spray inoculation trials with F. culmorum (Buerstmayr et al. 1999).

The aims of the present study were to estimate the GCA and SCA effects controlling type II FHB resistance across environments in a set of European winter wheat varieties and, for purposes of future selection, to identify potential combinations of parents with suitable levels of FHB resistance.

\section{Material and Methods}

Eight winter wheat varieties were crossed in all possible pairwise combinations and without reciprocals to produce $28 \mathrm{~F}_{1}$ lines. The parental genotypes were chosen on the basis of their overall resistance to FHB (Chrpová et al. 2012). The parental winter wheat varieties (Table S1*) are currently listed in the Czech National List (http://eagri.cz/public/app/ sok/odrudyNouQF.do?lang=en_US). The variety 'Petrus' was also included as parent in the diallel because it is a well-characterized source of FHB resistance in western Euro-

*Further details about the Electronic Supplementary Material (ESM) can be found at the end of the article. 
pean winter wheat that could be of great value in European breeding programmes (Gosman et al. 2007).

The resistance levels of the parents and $F_{1}$ crosses were evaluated in two years (2013 and 2014) and in two environments (field and greenhouse). Thus, there were four experiments altogether.

The parents and $\mathrm{F}_{1}$ crosses were planted in hill plots in three replications in field conditions and also in sheltered boxes (unheated greenhouses). Spikes were artificially inoculated using highly pathogenic isolate B of Fusarium culmorum (Šíp et al. 2002) at the phase of full flowering (BBCH 65). Inoculum (conidial suspension $0.8 \times 10^{7} / \mathrm{ml}$ ) was sprayed one time onto bunches of 5 flowering spikes randomly selected within hill plots. Inoculation dates for individual varieties or $\mathrm{F}_{1}$ crosses differed according to their flowering times.

Inoculated spikes were then kept in polythene bags for $24 \mathrm{~h}$. To minimize year and location effects on results, it appeared necessary in these conditions to support disease development (as appropriate) by irrigating plots. Fusarium head blight symptoms (expressed as percentage of spikelets displaying such symptoms) were evaluated for three time periods (14, 21 and 28 days after inoculation). Seeds from infected spikes were analysed for DON content as determined by ELISA using RIDASCREEN ${ }^{\circledR}$ FAST DON kits from R-Biopharm GmbH, Darmstadt, Germany. DON content determination is described in detail by Chrpová et al. (2007).

$\mathrm{F}_{2}$ progenies derived from the varieties Bakfis and Sakura were also evaluated in field trials during 2014 and 2015. Plants of the $\mathrm{F}_{2}$ generation were grown on row plots $1 \mathrm{~m}$ long (plant spacing: $6 \times 22 \mathrm{~cm})$. The spore mixture $\left(0.8 \times 10^{7} \mathrm{ml}^{-1}\right)$ was applied at a rate of approximately $150 \mathrm{ml} / \mathrm{m}^{2}$ onto the heads using a hand sprayer on two dates: at full flowering ( $>50 \%$ of flowering spikes) and 1 week later. The resistance level of each $\mathrm{F}_{2}$ cross was evaluated as the percentage of plants having low-level FHB symptoms (VSS on levels 1,2 , and 3 of scale $1-9,1$ without symptoms), the average symptom score for each cross, and the DON content in randomly selected plants.

The UNISTAT 6.5 package (UNISTAT Ltd., London, UK) was used for statistical analyses. Analysis of variance (ANOVA) for individual environments (field and greenhouse) and across environments was performed to determine the sources of variation for percentage of FHB symptoms and DON content. Least-square means, based on a general linear model were used to estimate GCA and SCA effects of the $\mathrm{F}_{1}$ crosses across environments according to Griffing's (1956) experimental model 1.

\section{Results}

Parental varieties as well as $\mathrm{F}_{1}$ generations were evaluated under both field and greenhouse conditions in two years (2013 and 2014). Mean DON content and visual symptom score (VSS), representing the percentage of FHB spread, of the parental varieties are presented in Table 1. In evaluating the $\mathrm{F}_{1}$ generation, a strong negative heterosis effect was determined as compared to the mean for the parents (Table 2). The mean difference between real and expected DON content was $-20.8 \mathrm{mg} / \mathrm{kg}$ and that for spike infection 
Table 1. Mean DON content and symptom score of parental varieties in the individual experiments

\begin{tabular}{|c|c|c|c|c|}
\hline \multirow{2}{*}{ Parent } & \multicolumn{4}{|c|}{ DON content $(\mathrm{mg} / \mathrm{kg})$} \\
\hline & Field 2013 & Field 2014 & Greenhouse 2013 & Greenhouse 2014 \\
\hline Bakfis & 20.02 & 33.72 & 25.89 & 17.26 \\
\hline Biscay & 273.05 & 103.73 & 99.87 & 124.08 \\
\hline Bohemia & 89.23 & 53.60 & 49.72 & 42.27 \\
\hline Cubus & 136.11 & 23.23 & 108.37 & 80.58 \\
\hline Elly & 127.60 & 64.82 & 47.30 & 36.63 \\
\hline Federer & 32.02 & 34.03 & 66.61 & 78.18 \\
\hline Petrus & 43.55 & 26.78 & 104.73 & 93.66 \\
\hline Sakura & 43.92 & 11.63 & 59.72 & 21.91 \\
\hline \multirow[t]{2}{*}{ Mean } & 95.69 & 43.94 & 70.27 & 61.82 \\
\hline & \multicolumn{4}{|c|}{$\%$ FHB spread } \\
\hline Bakfis & 26.67 & 16.89 & 29.00 & 11.22 \\
\hline Biscay & 67.78 & 52.22 & 51.67 & 56.44 \\
\hline Bohemia & 40.00 & 10.78 & 26.44 & 5.56 \\
\hline Cubus & 55.56 & 5.78 & 46.44 & 43.78 \\
\hline Elly & 47.78 & 28.67 & 55.56 & 16.22 \\
\hline Federer & 20.11 & 18.33 & 25.22 & 18.78 \\
\hline Petrus & 20.00 & 4.56 & 32.22 & 18.22 \\
\hline Sakura & 24.11 & 8.22 & 18.78 & 9.00 \\
\hline Mean & 37.75 & 18.18 & 35.67 & 22.40 \\
\hline
\end{tabular}

\section{DON (mg/kg)}

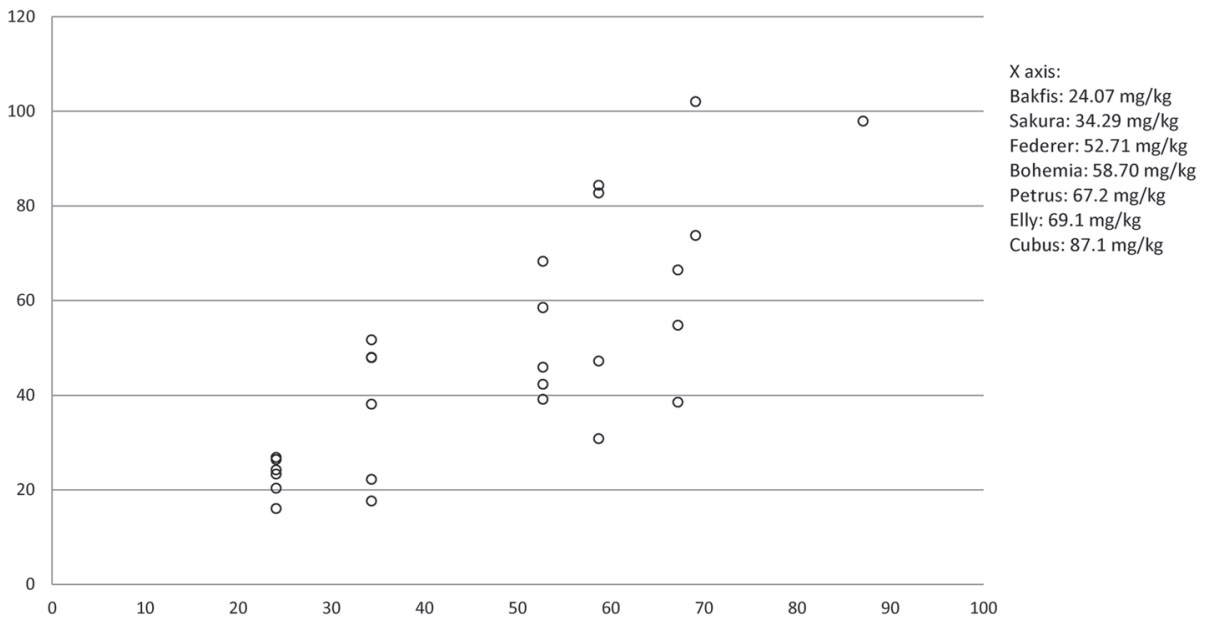

Figure 1. Comparing actual DON content $(\mathrm{mg} / \mathrm{kg})$ of the cross to DON content of the better parent $(\times$ axis $)$ 
Table 2. Heterosis of $\mathrm{F}_{1}$ generation crosses relative to the parents' average (MP) and to the "Better-more resistant" parent (BP) for DON content and spike infection ( $\mathrm{SH})$; mean values from four experiments from 2013 and 2014

\begin{tabular}{|c|c|c|c|c|c|c|c|}
\hline Crosses & & $\begin{array}{c}\text { DON } \\
(\mathrm{mg} / \mathrm{kg})\end{array}$ & MP & $\mathrm{BP}$ & $\begin{array}{l}\% \text { FHB } \\
\text { spread }\end{array}$ & MP & $\mathrm{BP}$ \\
\hline Sakura & Bakfis & 16.0 & -13.2 & -8.1 & 8.8 & -9.2 & -6.3 \\
\hline Sakura & Federer & 17.6 & -25.9 & -16.7 & 12.2 & -5.6 & -2.8 \\
\hline Petrus & Bakfis & 20.3 & -25.4 & -3.8 & 7.5 & -12.3 & -11.2 \\
\hline Sakura & Petrus & 22.2 & -28.6 & -12.1 & 9.1 & -7.8 & -5.9 \\
\hline Bakfis & Elly & 23.3 & -23.2 & -0.7 & 13.9 & -15.1 & -7.1 \\
\hline Cubus & Bakfis & 24.2 & -31.4 & 0.1 & 9.7 & -19.7 & -11.3 \\
\hline Bakfis & Biscay & 26.0 & -61.1 & 2.0 & 12.4 & -26.6 & -8.5 \\
\hline Federer & Bakfis & 26.4 & -12.0 & 2.4 & 10.3 & -10.5 & -10.3 \\
\hline Bakfis & Bohemia & 26.8 & -14.6 & 2.7 & 12.3 & -8.5 & -8.4 \\
\hline Petrus & Bohemia & 30.8 & -32.1 & -27.9 & 8.6 & -11.1 & -10.1 \\
\hline Sakura & Bohemia & 38.1 & -8.4 & 3.8 & 16.4 & -1.4 & 1.4 \\
\hline Petrus & Elly & 38.5 & -29.6 & -28.7 & 13.7 & -14.2 & -5.0 \\
\hline Federer & Bohemia & 39.1 & -16.6 & -13.6 & 14.1 & -6.5 & -6.5 \\
\hline Federer & Elly & 42.3 & -18.6 & -10.4 & 23.8 & -5.1 & 3.2 \\
\hline Federer & Petrus & 45.9 & -14.1 & -6.9 & 12.8 & -6.9 & -6.0 \\
\hline Bohemia & Elly & 47.5 & -16.4 & -11.2 & 21.9 & -7.0 & 1.2 \\
\hline Sakura & Elly & 47.9 & -3.8 & 13.6 & 13.8 & -12.2 & -1.2 \\
\hline Cubus & Sakura & 48.0 & -12.7 & 13.7 & 20.3 & -6.2 & 5.2 \\
\hline Sakura & Biscay & 51.7 & -40.6 & 17.4 & 21.9 & -14.1 & 6.9 \\
\hline Petrus & Biscay & 54.8 & -53.8 & -12.3 & 17.4 & -20.5 & -1.4 \\
\hline Federer & Cubus & 58.5 & -11.4 & 5.8 & 22.8 & -6.5 & 2.1 \\
\hline Petrus & Cubus & 66.4 & -10.8 & -0.8 & 22.5 & -5.8 & 3.8 \\
\hline Federer & Biscay & 68.2 & -33.2 & 15.5 & 24.5 & -14.3 & 3.9 \\
\hline Cubus & Elly & 73.7 & -4.4 & 4.6 & 24.8 & -12.7 & -12.3 \\
\hline Biscay & Bohemia & 82.7 & -21.7 & 24.0 & 28.5 & -10.3 & 7.9 \\
\hline Cubus & Bohemia & 84.3 & 11.5 & 25.6 & 28.6 & -0.7 & 7.9 \\
\hline Cubus & Biscay & 97.9 & -20.8 & 10.8 & 28.6 & -18.8 & -9.3 \\
\hline Biscay & Elly & 102.0 & -7.7 & 32.9 & 30.6 & -16.5 & -6.5 \\
\hline Average & & 47.2 & -20.8 & 1.8 & 17.6 & -10.9 & -3.1 \\
\hline
\end{tabular}

The values of general combining ability (GCA) for DON content and FHB spread (\%) are in bold 

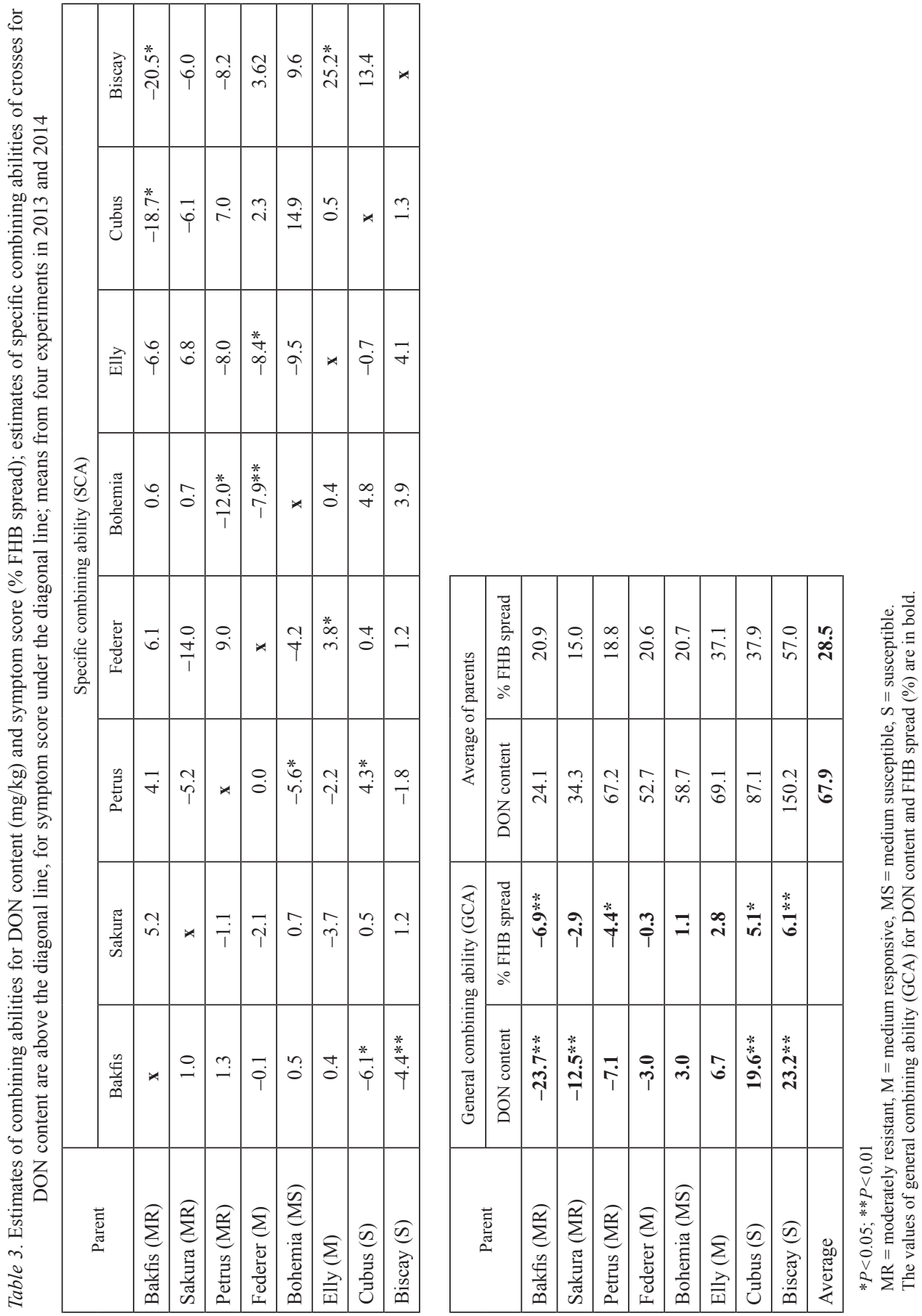
Table 4. Correlation coefficients $(r)$ between SCAs of the individual experiments (Field 2013 and 2014 and Greenhouse 2013 and 2014) for symptom score (\% FHB spread) and DON content $(n=28)$

\begin{tabular}{|l|c|c|c|c|c|c|c|c|}
\hline \multirow{2}{*}{ \% FHB spread } & Mean & & Field & 2013 & Field & 2014 & Greenhouse & 2013 \\
\cline { 2 - 10 } & $\mathrm{r}$ & $\mathrm{P}$ & $\mathrm{r}$ & $\mathrm{P}$ & $\mathrm{r}$ & $\mathrm{P}$ & $\mathrm{r}$ & $\mathrm{P}$ \\
\hline Field 2013 & $\mathbf{0 . 6 4 0}$ & 0.0001 & & & & & & \\
\hline Field 2014 & $\mathbf{0 . 3 7 3}$ & 0.0254 & $\mathbf{0 . 0 5 2}$ & 0.3966 & & & & \\
\hline Greenhouse 2013 & $\mathbf{0 . 7 1 4}$ & 0.0000 & $\mathbf{0 . 3 6 4}$ & 0.0285 & $\mathbf{- 0 . 1 8 4}$ & 0.1742 & & \\
\hline Greenhouse 2014 & $\mathbf{0 . 5 8 2}$ & 0.0006 & $\mathbf{0 . 0 4 5}$ & 0.4110 & $\mathbf{- 0 . 1 3 0}$ & 0.2553 & $\mathbf{0 . 5 3 0}$ & 0.0018 \\
\hline \multirow{2}{*}{ DON } & Mean & & Field & 2013 & Field & 2014 & Greenhouse & 2013 \\
\cline { 2 - 9 } & $\mathrm{r}$ & $\mathrm{P}$ & $\mathrm{r}$ & $\mathrm{P}$ & $\mathrm{r}$ & $\mathrm{P}$ & $\mathrm{r}$ & $\mathrm{P}$ \\
\hline Field 2013 & $\mathbf{0 . 6 6 8}$ & 0.0001 & & & & & & \\
\hline Field 2014 & $\mathbf{0 . 3 7 4}$ & 0.0249 & $\mathbf{- 0 . 0 1 8}$ & 0.4630 & & & & \\
\hline Greenhouse 2013 & $\mathbf{0 . 8 8 7}$ & 0.0000 & $\mathbf{0 . 4 9 7}$ & 0.0036 & $\mathbf{0 . 1 0 1}$ & 0.3047 & & \\
\hline Greenhouse 2014 & $\mathbf{0 . 6 2 1}$ & 0.0002 & $\mathbf{0 . 2 4 0}$ & 0.1096 & $\mathbf{0 . 0 1 5}$ & 0.4704 & $\mathbf{0 . 4 9 6}$ & 0.0036 \\
\hline
\end{tabular}

Note: Correlation coefficients are in bold.

$-10.9 \%$. The determined DON content was lower than the expected DON (parents' mean) in all cases other than one, that exception being the Cubus/Bohemia cross. The largest differences between the real and expected DON content and the real and expected spike infection were determined in the Bakfis/Biscay (-61.1/-26.6) and Petrus/Biscay $(-53.8 /-20.5)$ crosses. The Petrus/Biscay cross, however, exhibited almost double the DON content as compared to the Bakfis/Biscay cross. Figure 1 indicates a balanced low DON content in crosses with the Bakfis variety (point $24.1 \mathrm{mg} / \mathrm{kg}$ on the $\mathrm{x}$ axis) and considerably greater variability of DON content in crosses with the similarly moderately resistant varieties Sakura, Federer, and Petrus. DON content in all seven crosses with the Bakfis variety were in the range $16.0-26.8 \mathrm{mg} / \mathrm{kg}$ (overall mean for the crosses was 47.2 $\mathrm{mg} / \mathrm{kg}$ ). This finding can be considered very serious and it was supported, too, by the results of the combining abilities analyses (Table 3). GCA was the highest for DON content and visual symptom score, and it was highly significant in the Bakfis variety $(-23.7 * *$; $-6.9 * *)$. The Sakura variety demonstrated a significant general effect only on decreasing the DON content, while that was true of the Petrus variety on decreasing the spike infection percentage. Significant effects on increasing DON content and spike infection were also demonstrated in the susceptible varieties Cubus and Biscay. SCA was significant in the cross of the Bakfis variety with the susceptible Cubus variety, and it was highly significant in its cross with the susceptible Biscay variety. It is also apparent that not every crossing of resistant parents will necessarily bring the expected effect. In evaluating heterosis of crosses in comparison to the "Better - more resistant" parent (BP), it was determined that crossing the Sakura and Federer varieties led to a significant decrease in DON content. Meanwhile, crossing Federer with Bakfis demonstrated an increase in DON content (Table 2). Statistical significance of specific effects from crosses on both DON content and spike infection were seen only infrequently, however, with that apparently being 


\begin{tabular}{|c|c|c|c|c|c|c|c|c|c|c|c|c|c|c|c|c|}
\hline 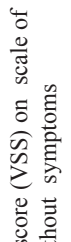 & 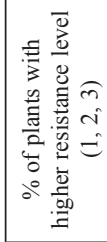 & $n$ & $i n$ & q & $\begin{array}{l}n \\
\text { y }\end{array}$ & $\begin{array}{l}\frac{n}{f} \\
\tilde{f}\end{array}$ & $\begin{array}{l}\stackrel{n}{f} \\
\dot{f}\end{array}$ & లి & ㄱ. & ñ & 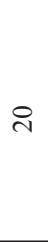 & 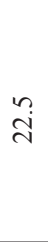 & $\stackrel{n}{\sim}$ & $\stackrel{n}{\sim}$ & तี & $\stackrel{n}{=}$ \\
\hline 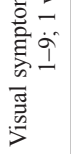 & 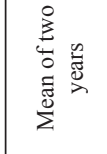 & $\stackrel{+}{i}$ & $\stackrel{\nabla}{i}$ & $\stackrel{\nabla}{r}$ & $\stackrel{\circ}{\dot{m}}$ & $\hat{i}$ & $\hat{i}$ & $\dot{r}$ & $\stackrel{m}{*}$ & $\stackrel{n}{n}$ & $\stackrel{+}{+}$ & $\stackrel{\circ}{\dot{m}}$ & $\dot{m}$ & 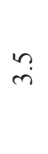 & $\stackrel{m}{*}$ & in \\
\hline & 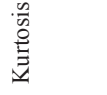 & $\stackrel{\Im}{\leftrightarrows}$ & 苞 & à & ڤे & $\tilde{n}$ & $\begin{array}{l}\dot{\sigma} \\
\dot{r}\end{array}$ & $\stackrel{t}{0}$ & $\stackrel{M}{\rightarrow}$ & $\stackrel{\hat{i}}{i}$ & $\tilde{\Omega}$ & $\stackrel{\circ}{\stackrel{+}{+}}$ & $\frac{a}{0}$ & $\stackrel{n}{n}$ & $\stackrel{m}{\stackrel{9}{i}}$ & $\begin{array}{l}\infty \\
\infty \\
\stackrel{\varphi}{\varphi}\end{array}$ \\
\hline & 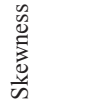 & $\stackrel{m}{\rightarrow}$ & $\stackrel{+}{m}$ & in & oे & $\stackrel{m}{=}$ & $\stackrel{\infty}{-\infty}$ & $\begin{array}{l}\infty \\
\infty \\
0\end{array}$ & $\hat{n}$ & $\stackrel{n}{n}$ & $\underset{F}{F}$ & $\stackrel{n}{a}$ & $\hat{m}$ & $\stackrel{g}{-}$ & : & $\stackrel{\infty}{\stackrel{0}{0}}$ \\
\hline & 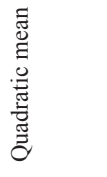 & $\underset{f}{\exists}$ & $\stackrel{n}{n}$ & $\stackrel{\text { సे }}{i}$ & $\stackrel{\stackrel{r}{i}}{i}$ & $\stackrel{\leftrightarrow}{\stackrel{\leftrightarrow}{\circ}}$ & $\begin{array}{l}\stackrel{0}{\sim} \\
\text { i }\end{array}$ & $\hat{\dot{m}}$ & $\stackrel{\infty}{\stackrel{\infty}{+}}$ & $\frac{0}{6}$ & $\underset{\substack{\infty \\
\sim}}{\stackrel{\infty}{0}}$ & $\stackrel{\curvearrowright}{\curvearrowright}$ & ô & $\begin{array}{l}\text { ?ִ } \\
=\end{array}$ & $\stackrel{8}{\circ}$ & $\begin{array}{l}\text { @o } \\
\text { in }\end{array}$ \\
\hline & 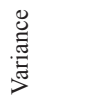 & $\stackrel{\infty}{m} \underset{\longrightarrow}{-}$ & $\stackrel{\circ}{\circ}$ & 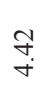 & $\begin{array}{l}\infty \\
\infty \\
\dot{m}\end{array}$ & ஜ: & $\vec{m}$ & 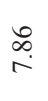 & $\begin{array}{l}\stackrel{0}{\infty} \\
\stackrel{\alpha}{ }\end{array}$ & $\stackrel{\vec{m}}{\stackrel{9}{2}}$ & $\stackrel{\text { fo }}{\stackrel{f}{f}}$ & $\begin{array}{l}\vec{b} \\
\stackrel{\sim}{\sim}\end{array}$ & $\underset{\substack{\infty \\
\stackrel{\infty}{d}}}{ }$ & 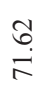 & $\begin{array}{l}\vec{\sigma} . \\
\text { } \\
\text { r. }\end{array}$ & $\begin{array}{l}\stackrel{\vartheta}{+} \\
\dot{f}\end{array}$ \\
\hline 官 & & ठ̊. & $\grave{ָ}$ & ָ̊ & $\stackrel{0}{=}$ & $\stackrel{f}{\circ}$ & 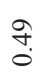 & $\stackrel{\sharp}{m}$ & $\begin{array}{l}\infty \\
\stackrel{\infty}{n}\end{array}$ & $\stackrel{m}{\stackrel{r}{+}}$ & $\vec{m}$ & in & $\stackrel{\vec{n}}{\dot{m}}$ & $\begin{array}{l}\stackrel{\circ}{+} \\
\stackrel{+}{2}\end{array}$ & $\begin{array}{l}\vec{f} \\
i n\end{array}$ & $\begin{array}{l}\stackrel{\infty}{N} \\
\stackrel{0}{0}\end{array}$ \\
\hline zo & 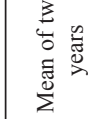 & 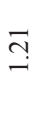 & $\stackrel{8}{:}$ & तै & $\stackrel{\overbrace{}}{i}$ & $\stackrel{\circ}{\stackrel{m}{m}}$ & $\tilde{n}$ & $\underset{r}{\tilde{r}}$ & $\begin{array}{l}\infty \\
\stackrel{+}{\infty}\end{array}$ & స్ర & 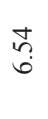 & $\underset{\sigma}{\stackrel{+}{0}}$ & $\hat{a}$ & $\underset{\infty}{\mathbb{\infty}}$ & $\begin{array}{l}\stackrel{2}{n} \\
\stackrel{0}{0}\end{array}$ & $\begin{array}{l}n \\
\stackrel{0}{0}\end{array}$ \\
\hline & $\begin{array}{l}0 \\
0 \\
6 \\
0 \\
0 \\
0 \\
\Sigma^{N} \\
x^{2}\end{array}$ & 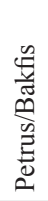 & 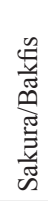 & 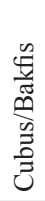 & 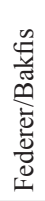 & 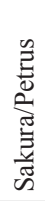 & 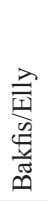 & 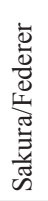 & 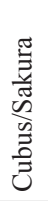 & 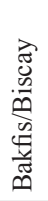 & 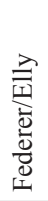 & 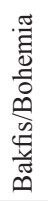 & 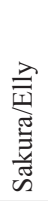 & 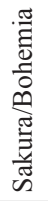 & 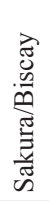 & 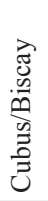 \\
\hline
\end{tabular}


due to differences in symptoms of infection between various experiments (in different environmental conditions), as documented by the correlation analysis (Table 4).

According to the mean evaluation, the best conditions were those of the experiments "Greenhouse 2013", "Field 2013", as well as "Greenhouse 2014" $(r=0.58-0.89$; $P<0.001$ ), while the conditions of Field 2014 were the least suitable (Table 4). SCA estimates in experiments "Field 2014" were not correlated significantly with the estimates obtained from the other experiments. The "Field 2014" experiment produced both the relatively lowest DON content $(36.5 \mathrm{mg} / \mathrm{kg}$; overall mean $=51.7 \mathrm{mg} / \mathrm{kg})$ and spike infection $(12.5 \%$; overall mean $=20.0 \%)$.

Evaluation of crosses in the $\mathrm{F}_{1}$ generation was followed by evaluation of selected crosses (derived from the Bakfis and Sakura varieties) in the $\mathrm{F}_{2}$ generation (Table 5). This was performed in 2014 and then repeated in 2015. In evaluating the progeny in the $F_{2}$ generation, highly significant correlation was determined between evaluations in the $\mathrm{F}_{1}$ and $\mathrm{F}_{2}$ generations both for DON content $(r=0.7803)$ and for visual symptom score $(r=0.7856)$ as well as between the individual experiments (and also in different years). The sole exception here was seen for the $F_{1} 2014$ field experiment. The experiments have confirmed the importance of evaluation already in the $\mathrm{F}_{1}$ generation. Visual symptom score in $\mathrm{F}_{1}$ correlated very well $(r=0.8008)$ with the percentage of resistant plants in the $\mathrm{F}_{2}$ generation (VSS on levels 1, 2, and 3 of scale 1-9). Further information on combining abilities of parental varieties was provided by statistical evaluation of crosses in the $\mathrm{F}_{2}$ generation. The low medians determined in the Petrus/Bakfis and Cubus/Bakfis combinations ensure a high proportion of resistant material in the hybrid generation. Evaluations of skewness and kurtosis also have informative value. Skewness indicates the extent to which values are symmetrically distributed around the selected central value or whether the distributed of the values is skewed to one side or the other (as were the cases for Bakfis/Bohemia and Sakura/Bohemia). Kurtosis indicates the shape of the probability distribution in relation to the central value. The higher the kurtosis in a distribution, the more tightly the values are concentrated around the central value.

\section{Discussion}

For selected parents, a hypothesis was verified that the level of resistance to Fusarium head blight can be detected on the basis of evaluation of symptomatic manifestation and content of the DON mycotoxin in early generations after the cross process (especially in $\mathrm{F}_{1}$ and $\mathrm{F}_{2}$ ). The seriousness of assessment of specific combination abilities is justified especially through the significantly different application of parent varieties and still rather negative experience during the use of remote forms with high resistance (e.g. Sumai3) in the breeding process (Kosová et al. 2009). A prospective strategy in the breeding of wheat seems to be the use of the varieties adapted to European conditions - Ittu et al. (2002). The data concerning the level of resistance to Fusarium head blight of these varieties is, however, many times insufficient. A possible solution is represented by determination of the general combination ability and specific combination ability, which enables identification of better parent lines (Hallauer et al. 2010). 
The experiments reached methodological conclusions useful in breeding for resistance to FHB and in agricultural practice.

In evaluating the $\mathrm{F}_{1}$ generation, a strong negative heterosis effect was determined as compared to the mean for the parent. This finding appears to be prospective for both classical breeding focused on creation of line varieties and for direct use of the heterosis effect for hybrid wheat (reduction of the DON content as well as of symptomatic manifestation). Heterosis is generally manifested in the form of larger performance and lifetime of the $\mathrm{F}_{1}$ generation hybrids, arising through the cross process of suitably combining parent forms. The heterosis effect detection is a significant finding in the case of characteristics associated with resistance to Fusarium head blight. Similar conclusions were derived also by other studies, when it was found out that even where parental material is moderately susceptible, anecdotal evidence suggests that transgressive segregation may be an important factor in FHB-resistance breeding as evidenced by three widely used varieties, Ernie, Sumai3, and Truman, each of which was derived from moderately susceptible parents (McKendry et al. 1995, 2005; Bai et al. 2000). In that study it was evidenced that the low content of DON can be achieved even after the cross process of the susceptible variety with a moderately resistant variety (Cubus/Bakfis).

A statistically significant correlation between evaluations in the $\mathrm{F}_{1}$ and $\mathrm{F}_{2}$ generations for the two characteristics monitored (symptom score, DON content) confirms the importance of the evaluation of resistance to Fusarium head blight in the $\mathrm{F}_{1}$ generation. Also, estimations of the general combination ability and specific combination ability were positively reflected in the parameters discovered in the splitting $F_{2}$ generation. In the $F_{2}$ generation, like in the $\mathrm{F}_{1}$ generation, the series of crossbreds with the Bakfis variety stated, on average, a significantly lower DON content and higher $\%$ of resistant plants according to symptomatic evaluation, compared to the series of crossbreds with the Sakura variety featuring a similar slight resistance. The revealing of the specific combination ability highly depends, without any doubt, on exactness of determination of the level of resistance at parent varieties. As far as our experiments are concerned, an exceptional position was achieved especially by the Cubus (susceptible)/Bakfis (resistant) crossbred which stated, in the experiments held in 2013 even the lowest average DON content exceptional characteristics (low median, etc.) were demonstrated also in $\mathrm{F}_{2}$.

While evaluating resistance to Fusarium head blight, it is necessary to establish suitable conditions for disease development (with the use of irrigation, or in the controlled environment). In this study it was found out that the results of 2014 from field conditions, when the lowest DON content as well as the lowest spike infection were achieved, differed from the other results. The reason was formed of worse conditions for disease development and DON accumulation. The interaction of the genotype with the environment in relation to manifestations of resistance to Fusarium head blight was described in a number of studies (Mesterházy 1995; Miedaner et al. 2001; Zwart et al. 2008).

Evaluation of resistance to Fusarium head blight in the $\mathrm{F}_{1}$ or $\mathrm{F}_{2}$ generations is not commonly carried out in the breeding practice. The reason is especially shortage of seeds in early generations as well as work demands. The results obtained indicate that the use of this method has its substantiation and it is suitable especially during the cross process of 
parent varieties with an unknown level of resistance, where it is possible to obtain, on the basis of the results of evaluation of resistance in the $\mathrm{F}_{1}$ generation, an idea of prospects of this combination from the viewpoint of resistance to Fusarium head blight. Another possibility is to make use of heterosis directly for acquiring resistance in hybrid wheat.

\section{Acknowledgements}

The authors thank to Š. Bártová and D. Pátková for technical assistance. This research was supported by the Ministry of Agriculture of the Czech Republic, institutional support MZE RO0416 and project NAZV QJ 1210189.

\section{References}

Bai, G.H., Shaner, G., Ohm, H. 2000. Inheritance of resistance to Fusarium graminearum in wheat. Theor. Appl. Genet. 100:1-8.

Becher, R., Miedaner, T., Wirsel, S.G.R. 2013. Biology, diversity, and management of FHB-causing Fusarium species in small-grain cereals. In: Kempken, F., Esser, K. (eds), The Mycota. A Comprehensive Treatise on Fungi as Experimental Systems for Basic and Applied Research. 2nd edn. Springer. Heidelberg, Germany. pp. 199-241.

Boeven, H.G., Würschum, T., Weissmann, S., Miedaner, T., Maurer, H.P. 2016. Prediction of hybrid performance for Fusarium head blight resistance in triticale (3Triticosecale Wittmack). Euphytica 207:475-490.

Buerstmayr, H., Lemmens, M., Berlakovich, S., Ruckenbauer P. 1999. Combining ability of resistance to head blight caused by Fusarium culmorum (W.G. Smith) in the F1 of a seven parent diallel of winter wheat (Triticum aestivum L.). Euphytica 110:199-206.

Chrpová, J., Šíp, V., Matějová, E., Sýkorová, S. 2007. Resistance of winter wheat varieties registered in the Czech Republic to mycotoxin accumulation in grain following inoculation with Fusarium culmorum. Czech J. of Genetics and Plant Breeding 43:44-52.

Chrpová, J., Šíp, V., Štočková, L., Dumalasová, V. 2012. Evaluation of Fusarium head blight resistance in wheat under high infection pressure in field conditions. Cereal Res. Commun. 40:396-404.

Gosman, N., Bayles, R., Jennings, P., Kirby, J., Nicholson, P. 2007. Evaluation and characterization of resistance to Fusarium head blight caused by Fusarium culmorum in UK winter wheat cultivars. Plant Pathol. 56:264-276.

Griffing, B. 1956. Concept of general and speciffc combining ability in relation to diallel crossing systems. Aust. J. Biol. Sci. 9:463-493.

Hall, M.D., Van Sanford, D.A. 2003. Diallel analysis of Fusarium head blight resistance in soft red winter wheat. Crop Sci. 43:1663-1670.

Hallauer, A.R., Carena, M.J., Filho, J.B.M. 2010. Quantitative Genetics in Maize Breeding. Handbook of Plant Breeding Vol. 6. Springer. New York, USA. 663 p.

Ittu, M., Saulescu, N.N., Ittu, G., Moldovan, M. 2002. Approaches in breeding wheat for resistance to FHB in Romania. Petria 12:67-72.

Jiang, G.L., Ward, R.W. 2006. Inheritance of resistance to Fusarium head blight in the wheat lines 'CJ 9306' and 'CJ 9403'. Plant Breed. 125:417-423.

Kosová, K., Chrpová, J., Šíp, V. 2009. Cereal resistance to Fusarium head blight and possibilities of its improvement through breeding. Czech J. of Genetics and Plant Breeding 45:87-105.

McKendry, A.L., Berg, J.E., Tague, D.N., Kephart, K.D. 1995. Registration of 'Ernie' wheat. Crop Sci. 35:1513-1514.

McKendry, A.L., Tague, D.N., Wright, R.L., Tremain, J.A., Conley, S.P. 2005. Registration of 'Truman' wheat. Crop Sci. 45:421-423. 
Mesterházy, Á. 1995. Types and composition of resistance to Fusarium head blight of wheat. Plant Breed. 114:377-386.

Mesterházy, Á. 2002. Role of deoxynivalenol in aggressiveness of Fusarium graminearum and F. culmorum and in resistence to Fusarium head blight. European J. Plant Pathol. 108:675-684.

Miedaner, T., Reinbrecht, C., Lauber, U., Schollenberger, M., Geiger, H.H. 2001. Effects of genotype and genotype-environment interaction on deoxynivalenol accumulation and resistance to Fusarium head blight in rye, triticale, and wheat. Plant Breed. 120:97-105.

Oettler, G., Tams, S.H., Utz, H.F., Bauer, E., Melchinger, A.E. 2005. Prospects for hybrid breeding in winter triticale: I. Heterosis and combining ability for agronomic traits in European elite germplasm. Crop Sci. 45:1476-1482.

Smith, O.S. 1986. Covariance between line per se and testcross performance. Crop Sci. 26:540-543.

Šíp, V., Sýkorová, S., Stuchlíková, E., Chrpová, J. 2002. The effect of infection with Fusarium culmorum L. on deoxynivalenol content in grain of selected winter wheat varieties. J. Appl. Genet. 43A:319-332.

Šíp, V., Chrpová, J., Leišová, L., Sýkorová, S., Kučera L., Ovesná, J. 2007. Effects of genotype, environment and fungicide treatment on development of Fusarium head blight and accumulation of DON in winter wheat grain. Czech J. of Genetics and Plant Breeding 43:16-31.

Zwart, R.S., Muylle H., Van Huylenbroeck, J., Van Bockstaele, E., Roldán-Ruiz, I. 2008. Combining ability analysis of Fusarium head blight resistance in western European wheat lines. Euphytica 162:449-456.

\section{Electronic Supplementary Material (ESM)}

Electronic Supplementary Material (ESM) associated with this article can be found at the website of CRC at http://www.akademiai.com/content/120427/

Electronic Supplementary Table S1. Variety name, breeding company, pedigree and Fusarium head blight (FHB) resistance score of the eight European winter wheat varieties used as parents in the half-diallel 